\title{
ANÁLISE DA IMPLEMENTAÇÃO DE ESTRATÉGIA EM EMPRESA HOSPITALAR COM USO DE MAPAS COGNITIVOS
}

AN ANALYSIS OF STRATEGY IMPLEMENTATION IN A HOSPITAL USING COGNITIVE MAPS

\section{RESUMO}

Este artigo analisa os fatores de influência na implementação de uma estratégia no ambiente hospitalar. Tal estratégia é a implementação do Time de Resposta Rápida em unidades de internação, buscando qualidade e segurança na assistência ao paciente hospitalizado. A escolha baseou-se em analisar uma estratégia que tivesse gerado resultados positivos para a instituição em estudo. O trabalho utilizou-se de pesquisa qualitativa de caráter exploratório, sendo um Estudo de Caso único, realizado em um hospital privado de Porto Alegre (RS). Foram realizadas entrevistas em profundidade e também foram aplicados Mapas Cognitivos Causais. Como resultados da pesquisa, o fator diferencial identificado que determinou o sucesso da implementação do Time de Resposta Rápida foi o componente humano. Tal processo em estudo também teve êxito pela congregação de múltiplos fatores que se tornaram facilitadores para garantir esse sucesso. Como contribuição acadêmica, o Mapeamento Cognitivo traz uma possibilidade para compreender-se melhor o pensamento dos níveis hierárquicos no processo da estratégia.

\section{Peter Bent Hansen}

Professor do Programa de Pós-Graduação em Administração, Faculdade de Administração, Contabilidade e Economia, Pontifícia Universidade Católica do Rio Grande do Sul - RS, Brasil

peter.hansen@pucrs.br

\section{Fernanda de Menezes Guimarães}

Coordenadora do Centro de Enfermagem de Pacientes Externos, Hospital Mãe de Deus - RS, Brasil nanda_guima@hotmail.com

Recebido em 30.03.2008. Aprovado em 08.07.2009

Avaliado pelo sistema double blind review

Editores Científicos: Organizadores do Fórum

ABSTRACT This paper analyses the factors affecting the implementation of a strategy within the hospital environment. Such strategy is the implementation of the Quick Response Team in hospitalization units, pursuing quality and safe services to the patient. The choice was based in the analysis of a strategy rendering positive results to the studied institution. A qualitative exploratory research was used, being a single case study within a private hospital located at Porto Alegre, Rio Grande do Sul, Brazil. In-Depth interviews and Causal Cognitive Maps were applied. The research results have shown that the differential factor determining the implementation success of the Quick Response Team was the human component. The studied process was also successful due to the confluence of multiple factors, which have become facilitators to assure such a success. As an academic contribution, the Cognitive Mapping brings an opportunity to better understanding the hierarchic levels when thinking about the strategy process.

PALAVRAS-CHAVE Assistência à saúde, ambiente hospitalar privado, estratégia hospitalar, mapas cognitivos, processo de estratégia. KEYWORDS Healthcare, private hospital environment, healthcare strategy, cognitive maps, strategy process. 


\section{INTRODUÇÃO}

Os negócios no cenário globalizado atual desenvolvem-se em um ritmo dinâmico, influenciados por várias mudanças externas, criando a necessidade de as organizações buscarem estratégias claras e consistentes.

Ao estabelecerem-se estratégias, não somente sua formulação é importante, mas, sobretudo a garantia da sua implementação, para que se obtenham resultados consistentes ao longo do tempo. Implementar as estratégias propostas, na maioria das vezes, requer mudanças organizacionais, tecnológicas e comportamentais que afetam os indivíduos e a própria organização num processo cíclico de mudanças (FREEDMAN, 2003). Essa implementação requer habilidades gerenciais que são distintas daquelas exigidas para a formulação das estratégias. De certa maneira, observa-se que a implementação é uma etapa crítica, pois é ela que determina o sucesso ou o fracasso da estratégia: é onde se concretiza a ação.

Muitos podem ser os fatores que desviam as organizações de seus objetivos estratégicos, fazendo com que o planejamento não se concretize. Chaharbaghi e Feurer (1995) e Mintzberg e Quinn (2001) apresentam o que chamam de fatores essenciais para que se realize a implementação da estratégia, que nada mais são do que o alinhamento da estrutura, sistemas, pessoas e processos para o sucesso dessa implementação.

Em ambientes organizacionais dinâmicos e complexos, a implementação das estratégias parece ser um processo difícil de ser conduzido, principalmente porque depende do envolvimento direto das pessoas. $\mathrm{Na}$ área de serviços, mais precisamente na área hospitalar, o componente de envolvimento humano é acentuado, por conta das peculiaridades do setor. Mintzberg e Quinn (2001) realizam uma análise das estratégicas em empresas com perfil hospitalar. Nesse tipo de organização, os autores referem que a estrutura geralmente segue a forma de burocracia profissional, pois depende de habilidades e conhecimentos técnicos específicos de cada profissional. Esses profissionais alinham-se em associações que definem suas melhores práticas, padronizando o exercício profissional. A autoridade passa a ser de natureza profissional, estando nas mãos dos experts, que são grupos de profissionais técnico-científicos com diferentes tipos de relacionamentos com a empresa hospitalar. Os médicos, por suas características de autonomia profissional e conhecimento técnico específico, determinam relações de poder no hospital. Dessa forma, a coordenação nesse tipo de organização hospitalar é descentralizada, sendo uma estrutura administrativa democrática.
Além disso, Mezomo (1995) também reforça a dificuldade da departamentalização dos hospitais, o que torna essas empresas mais inflexíveis e mais sujeitas aos interesses próprios de departamentos. Nesse contexto, criam-se "feudos" que também dificultam a implementação da estratégia, na medida em que essa estratégia não estiver de acordo com os interesses do setor ou de diferentes stakeholders (dirigentes, médicos, enfermeiros, pacientes, fontes pagadoras, entre outros) que podem ser conflitantes entre si. Na implementação de uma estratégia, é necessário considerar os diferentes interesses favoráveis ou não à estratégia. Embora ainda haja departamentalização, alguns hospitais já estão trabalhando de forma mais flexível, promovendo a participação das pessoas nos processos de tomada de decisão e projetos multidisciplinares e aproximando os médicos das decisões estratégicas do hospital. A parte-chave dessas organizações é a eficiência operacional, que no hospital está na área médico-assistencial. Nesse tipo de empresa, é necessária intensa negociação, pois pode haver certa dispersão de poder, principalmente na implementação de projetos de interesses distintos. Estes são alguns dos fatores que tornam a implementação das estratégias no hospital uma situação peculiar.

Pelo exposto, o componente humano no processo de implementação das estratégias é determinante para que as ações se efetivem. Jardim (2001) aborda a relevância de se considerar os aspectos subjetivos para estabelecer estratégias de ação. Da mesma forma, Bastos (2002) e Ribeiro (2003) referem as crescentes pesquisas no campo da cognição organizacional, sendo centrais para o sucesso ou fracasso de planos estratégicos das organizações.

O presente artigo analisa os fatores que influenciam a implementação de uma estratégia médico-assistencial específica no ambiente hospitalar privado da Saúde Complementar, a partir da percepção de seus dirigentes e operadores, distribuídos em seus níveis hierárquicos.

\section{ESTRATÉGIAS NA ÁREA HOSPITALAR E SUA IMPLEMENTAÇÃO}

Para garantir espaço na competitividade atual do setor da Saúde, os hospitais privados necessitam relevantes investimentos não só tecnológicos, mas de metodologias e programas que auxiliem na obtenção de diferenciais competitivos, como as certificações nacionais e internacionais, entre outros. Para isto é necessário estabelecer objetivos e traçar as estratégias para alcançá-los. 
Segundo Zanon (2001), Cohn e Elias (2005), a área hospitalar tem se modificado ao longo dos últimos anos no que diz respeito aos seus processos e à sua forma de gestão. Atualmente, a preocupação é a busca constante de melhoria, com recursos focados em qualidade assistencial e uma gestão baseada em evidências. Para Porter e Teisberg (2007, p. 21), a solução das questões da Saúde está alicerçada nas estratégias de competição baseadas em valor e resultados. Esses autores referem que "a maneira de transformar o sistema de saúde é realinhar a competição com o valor para os pacientes". No entanto, salientam os mesmos que na prática o foco está na minimização dos custos e na luta por quem vai pagar esses custos. Assim sendo, essas estratégias geram um resultado onde as estruturas organizacionais e suas práticas estão desalinhadas com o valor para o paciente.

O hospital, sendo um sistema integrado em vários aspectos e inserido em um contexto conturbado como o da saúde, necessita de planejamento e de tomada de decisão estratégica. Oliva e Borba (2004) destacam a necessidade de o hospital desenvolver estratégia de excelência hospitalar nos seus serviços, caso contrário, corre o risco de desaparecer. Tal excelência seria fruto do comprometimento com a resolubilidade, qualidade assistencial e custos aceitáveis. No entanto, Porter e Teisberg (2007, p. 20) referem que nem sempre o "preço da excelência" justifica os altos custos com a saúde.

São múltiplos os fatores que interagem no desempenho de uma organização hospitalar, como: a necessidade de capacitação e integração da equipe, a velocidade das transformações tecnológicas e da geração de conhecimento e a diversidade de processos advindos das práticas assistenciais. Nessas condições, para se obter os resultados desejados tal organização requer processos flexíveis, atuações afinadas dos profissionais entre si e alinhadas às estratégias da organização.

Nos hospitais, como em outras organizações onde as habilidades e conhecimento profissionais são aspectos básicos para o desempenho organizacional, as pessoas são elementos-chave para qualquer implementação que se deseje realizar nesse ambiente. No entanto, apesar das resistências humanas naturais, existem também apoios e formas de vencer esses obstáculos para que a estratégia seja implementada com sucesso. Hrebiniak (2006) e Thompson Jr. e Strickland III (2000) citam a importância da formação de competências básicas na implementação das estratégias, gerando vantagem competitiva. Esses autores afirmam que sem o efetivo envolvimento das pessoas não existirá a implementação das estratégias em uma organização.

\section{Implementação das Estratégias}

A estratégia é o alicerce que fortalece as organizações para $o$ atingimento de suas metas, interagindo com os fatores externos que vão surgindo. A Estratégia na Administração é um plano unificado, abrangente e integrado que se propõe a assegurar que os objetivos principais da empresa sejam atingidos. Ela pode ser apresentada como um padrão de decisões que determina objetivos, propósitos, metas, políticas e planos além da escala de negócios e das regras de funcionamento da empresa (MINTZBERG e QUINN, 2001).

O processo da estratégia baseia-se fundamentalmente na formulação e na implementação da estratégia, que é definida como resultado de uma análise sobre as oportunidades externas e as habilidades internas, promovendo um equilíbrio (MINTZBERG e QUINN, 2001). Hrebiniak (2006, p. 28) refere que é necessário existir a interdependência entre a formulação e a implementação da estratégia, citando como consequência dessa "visão simultânea" o sucesso dessa implementação. Ao formular a estratégia, deve-se ter em mente como será sua execução, antecipando problemas que possam advir do processo de implementação. Mintzberg e Quinn (2001), Freedman (2003) e Silva (2001) também apresentam o processo da Estratégia como sendo composto pela formulação e pela implementação, interligadas de forma interativa e complexa.

$\mathrm{Na}$ implementação, ao contrário da formulação da estratégia, todas as pessoas da organização necessitam ser envolvidas no processo, assim como todas as unidades de negócios e de apoio. Portanto, a implementação leva à análise através do monitoramento do impacto de cada ação proposta sobre clientes, mercado e comunidades (SENGE e outros,1999; O'REGAN e GHOBADIAN, 2002; e KAPLAN e NORTON, 2000). Dessa forma, segundo Freedman (2003) e Mintzberg e outros (2006), o papel da liderança pessoal é fator decisivo na realização da estratégia, pois sua implementação passa a ser o trabalho do dia-a-dia na organização, onde cada um necessita realizar o seu trabalho corretamente.

A implementação da estratégia necessita ser acompanhada de forma sistemática ao longo de sua execução, pois é um processo dinâmico e adaptativo e não uma ação isolada (HREBINIAK, 2006). Vasconcelos Filho e Pagnoncelli (2001) também referem que não basta fazer planos, pois estes não são "auto-implantáveis"; é necessário o acompanhamento sistemático.

Nessa etapa de implementação, pode-se usar o Balanced Scorecard (BSC), uma ferramenta gerencial abrangente que traduz os objetivos estratégicos da empresa através de um conjunto de indicadores de desempenho, servindo 
de base para um sistema de medição e gestão estratégica, utilizando ativos tangíveis e intangíveis. Com esse sistema é possível identificar em que áreas críticas a empresa necessita realizar melhorias: clientes, produtos, processos e mercados (KAPLAN e NORTON, 2000).

Mintzberg e Quinn (2001), O'Regan e Ghobadian (2002), Freedman (2003), Kaplan e Norton (2000, 1997) e Hrebiniak (2006) referem que a má implementação é a maior responsável pelo fracasso da estratégia. Tal situação pode ser resultante da inabilidade das empresas em detectar e superar as dificuldades de implementação, ou ser decorrente das armadilhas e dificuldades de implementação.

\section{Dificuldades na implementação de estratégias}

Considerando-se que, no Brasil, segundo pesquisas realizadas em diversos tipos de empresas, menos que $10 \%$ das estratégias empresariais são eficientemente formuladas e executadas (RUAS, 2003), a avaliação do processo de implementação de estratégia passa a ser relevante.

Tomando como base os obstáculos à implementação da estratégia descritos por Hrebiniak (2006), por considerar-se essa abordagem a mais abrangente em relação à descrição de outros autores, buscou-se um maior detalhamento das dificuldades de implementação de estratégias, com vistas à construção de um roteiro para a pesquisa de campo na organização estudada. Assim:

1) Incapacidade de gerenciar mudanças ou a resistência a ela: são causas primordiais para o insucesso na execução da estratégia, pois provocam uma inércia estratégica que é, simplesmente, o fato de "não começar" a ação de implementação da estratégia. É um fator determinante se considerado que a implementação da estratégia é um processo de mudança que também envolve mudança de cultura.

2) Conflito de poder: é um elemento complexo na organização, que pode determinar o fracasso da estratégia. Muito influenciado pelo tipo de relacionamento entre os profissionais e seus interesses na estratégia.

3) Comunicação inadequada: é a falta de clareza da estratégia, associada à falta de clareza da liderança e do time superior sobre a estratégia corporativa, podendo gerar o isolamento estratégico.

4) Indefinição de responsabilidades: é o compartilhamento deficiente das informações ou a transferência fraca de conhecimento e falta de responsabilidades, desintegrando as unidades organizacionais.

5) Estratégia vaga e ineficiente: é a impossibilidade de mensuração da estratégia.

6) Falta de comprometimento: é a falta de convicção e de participação na execução das ações de implementação.

7) Falta de modelo orientador: é a inexistência de um modelo de implementação, dificultando uma visão simultânea do planejamento e realização da estratégia, pois leva a um desvio estratégico no processo de execução.

8) Falta de clareza na estrutura e no processo: é a falha no entendimento do processo, sendo uma ausência de métricas que localizam a posição da organização no processo de implementação da estratégia, planos imprecisos que não possibilitam o alinhamento de objetivos e estratégias em todos os níveis da organização.

9) Falta de convicção na execução: é vinculada à necessidade do sentimento de "pertença" em todos os níveis gerenciais da organização, principalmente o nível operacional. Está ligada à falta de comprometimento.

10) Falta de incentivos: é relacionada ao apoio da direção e à falta de reconhecimento pelos resultados parciais obtidos durante o processo de implementação da estratégia.

11) Recursos financeiros insuficientes: é um item dos mais importantes, pois a aprovação de um planejamento de execução e de seus recursos financeiros correspondentes é condição básica para o início da implementação da estratégia.

12) Falta de apoio da direção: é decorrente de uma visão mais imediatista com relação aos resultados do processo de implementação da estratégia.

Os fatores identificados por Hrebiniak (2006) serão aqueles considerados e explorados no caso em estudo.

\section{MÉTODO DE PESQUISA EMPREGADO}

O trabalho utilizou-se de uma pesquisa qualitativa de caráter exploratório. Como estratégia de pesquisa foi utilizado o Estudo de Caso único.

A pesquisa foi realizada no Hospital Mãe de Deus (HMD), em Porto Alegre (RS), que é uma das unidades de negócio do Sistema de Saúde Mãe de Deus, com aproximadamente 400 leitos, atendendo clientes do Sistema de Saúde Privado. Trata-se de um hospital filantrópico, fundado há 30 anos pelas Irmãs Scalabrianas, que se integra aos hospitais privados da ANAHP (Associação Nacional de Hospitais Privados). Sua principal estratégia é o atendimento nas áreas de alta complexidade, com diferencial em qualidade e segurança no atendimento médico-hospitalar. Em termos de concorrência, esse hospital compete com outros hospitais privados que realizam procedimentos médicos e laboratoriais de alta complexidade na região metropolitana de Porto Alegre. 
A estratégia analisada no hospital foi escolhida a partir de uma entrevista inicial com o Superintendente (nível estratégico) da empresa. A pesquisa utilizou entrevistas em profundidade e uma metodologia interpretativa, o Mapeamento Cognitivo, precisamente através da aplicação de Mapas Cognitivos Causais e da Metodologia Strategic Options Development and Analysis (SODA). O roteiro das entrevistas foi semi-estruturado, baseando-se no modelo de Hrebiniak (2006) sobre os fatores que interferem na implementação de estratégias. Os resultados das entrevistas e dos mapas foram comparados entre si. Foram definidas duas metodologias para aferição da qualidade e da complementaridade das informações obtidas, visando ao aprofundamento do tema.

Dentre as metodologias interpretativas analisadas, foi escolhido o Mapeamento Cognitivo, por apresentar características julgadas adequadas para este estudo: a abordagem individual, a possibilidade de construir o coletivo a partir do individual, a possibilidade de construir mapas agregados (metodologia SODA), por permitir o pensamento divergente e o conflito entre os participantes, e como ferramenta apropriada para o processo estratégico (formulação e implementação). O método utilizado foi uma adaptação da metodologia SODA, descrita por Eden e outros (citados por PIDD, 2001). Muitos autores, como Jardim (2001), Bastos (2000, 2002) e Pidd (2001), entre outros, recomendam a utilização do Mapeamento Cognitivo como ferramenta de negociação e aprendizagem para construção da árvore de objetivos estratégicos, visando à implementação das ações planejadas e ao estudo do comportamento macro e micro-organizacional.

A Metodologia SODA segue três estágios no seu desenvolvimento. No primeiro, são entrevistadas as pessoas para construir seus mapas cognitivos individuais sobre a situação em estudo. No segundo estágio, o foco é unir e mesclar os mapas individuais (merging) e resultados, gerando um mapa estratégico único que retrata a percepção coletiva sobre o mesmo tema. Esse processo tem início com a procura de ligações, diferenças e semelhanças entre os mapas dos respondentes e gera uma agregação dos mapas individuais. Esse mapa agregado recebe a denominação de Mapa Estratégico ou Agregado. O terceiro estágio descreve a realização de workshops SODA, onde o Mapa Estratégico, resultante da fusão dos mapas individuais, passa a ser um veículo de discussão e negociação de ações entre os participantes do grupo. O Mapa Estratégico é o primeiro passo para auxiliar esse grupo no comprometimento com a ação negociada e consentida (PIDD, 2001).

Primeiramente, foram realizadas as entrevistas em profundidade com colaboradores de cada nível hierárquico.
As entrevistas ocorreram no respectivo ambiente de trabalho e tiveram duração diferenciada para os respondentes dos três níveis hierárquicos (estratégico, tático e operacional). A duração média das entrevistas nos três níveis foi de uma hora e 10 minutos. No total, foram entrevistados oito colaboradores distribuídos entre os níveis hierárquicos. Essa etapa é denominada de Fase 1 da pesquisa de campo.

A construção dos Mapas Cognitivos individuais foi realizada através de entrevistas, com duração média de uma hora e 40 minutos, também realizadas no ambiente dos entrevistados. Foram desenvolvidos um total de nove mapas cognitivos individuais, três por nível hierárquico (estratégico, tático, operacional). Essa etapa é denominada de Fase 2 da pesquisa de campo. Para o desenvolvimento dos mapas cognitivos individuais foi preparada uma sala exclusiva dentro do hospital, livre de interrupções e com o material necessário para a construção dos mapas (quadro branco, papel, pincel atômico de várias cores, cartelas adesivas grandes e pequenas e canetas). Primeiramente, foi explicado aos respondentes o que eram Mapas Cognitivos e como estes eram desenvolvidos; posteriormente, explicou-se o tema proposto na construção destes. Os Mapas Cognitivos Individuais foram construídos a partir de um roteiro referido por Jardim (2001) e Pidd (2001). A questão-chave apresentada aos respondentes foi: "O que afetou a implementação do Time de Resposta Rápida (TRR) no HMD?"

Para análise dos resultados da pesquisa procedeuse como a seguir. A partir dos nove Mapas Cognitivos individuais, foram construídos três Mapas Cognitivos Agregados, um para cada nível hierárquico. Tais Mapas agregados foram analisados de forma específica.

Por outro lado, as oito entrevistas em profundidade foram gravadas e transcritas. Posteriormente, foram geradas sínteses das entrevistas para cada nível hierárquico, num total de três sínteses. A análise desses dados foi realizada através do método de Análise de Conteúdo.

Por fim, ocorreu a comparação dos resultados dos Mapas Cognitivos Agregados com as sínteses das entrevistas, de forma global e por nível hierárquico, visando aprofundar e complementar a interpretação do tema.

Os respondentes dessa pesquisa obrigatoriamente eram integrantes da área assistencial do quadro funcional do referido hospital, que implementaram a estratégia nos três níveis hierárquicos, estratégico, tático e operacional. A escolha dos respondentes, tanto na fase das entrevistas como dos mapas cognitivos, foi por conveniência com critério não estatístico. Os respondentes da fase 1 foram distintos dos da fase 2 .

As características dos mesmos estão descritas no Quadro 1. 
Considerando os autores e pesquisadores deste estudo: o pesquisador 1 não tem vínculo com o hospital em estudo; é professor do Programa de Pós-Graduação em
Administração da Pontifícia Universidade Católica do Rio Grande do Sul; a entrevistadora e pesquisadora 2 tem vínculo com o hospital do estudo, sendo supervisora de

Quadro1 - Características dos participantes da pesquisa

\begin{tabular}{|c|c|c|c|c|c|c|c|}
\hline $\mathrm{N}^{0}$ & CARGO & ABRANGÊNCIA & TEMPO & INSTRUMENTO & DATA & LOCAL & DIFICULDADES \\
\hline 1 & Diretor executivo & Estratégica & 1:30h & $\begin{array}{c}\text { Entrevista } \\
\text { semiestruturada }\end{array}$ & 7.1.2007 & Diretoria & $\begin{array}{l}\text { Primeira } \\
\text { entrevista }\end{array}$ \\
\hline 2 & Diretor médico-científico & Estratégica & $1: 00 h$ & $\begin{array}{c}\text { Entrevista } \\
\text { semiestruturada }\end{array}$ & 31.1.2007 & Diretoria & Agendamento \\
\hline 3 & $\begin{array}{l}\text { Gestor médico do centro } \\
\text { de terapia intensiva }\end{array}$ & Tática & $0: 45 h$ & $\begin{array}{c}\text { Entrevista } \\
\text { semiestruturada }\end{array}$ & 11.1.2007 & CTI & Não \\
\hline 4 & $\begin{array}{l}\text { Gestor médico da } \\
\text { emergência }\end{array}$ & Tática & $1: 10 \mathrm{~h}$ & $\begin{array}{c}\text { Entrevista } \\
\text { semiestruturada }\end{array}$ & 17.1.2207 & Emergência & Não \\
\hline 5 & $\begin{array}{l}\text { Supervisora de enferma- } \\
\text { gem em emergência }\end{array}$ & Tática & $0: 55 h$ & $\begin{array}{c}\text { Entrevista } \\
\text { semiestruturada }\end{array}$ & 11.1.2007 & Emergência & Não \\
\hline 6 & $\begin{array}{c}\text { Enfermeira } \\
\text { Executiva da unidade } \\
\text { internação }\end{array}$ & Operacional & $1: 00 \mathrm{~h}$ & $\begin{array}{c}\text { Entrevista } \\
\text { semiestruturada }\end{array}$ & 10.1.2007 & Sala de RH & Não \\
\hline 7 & $\begin{array}{c}\text { Enfermeira } \\
\text { Executiva da unidade } \\
\text { internação }\end{array}$ & Operacional & $0: 50 \mathrm{~h}$ & $\begin{array}{c}\text { Entrevista } \\
\text { semiestruturada }\end{array}$ & 9.1 .2007 & Sala de RH & Não \\
\hline 8 & $\begin{array}{l}\text { Médico do time de } \\
\text { Resposta rápida }\end{array}$ & Operacional & 1:00h & $\begin{array}{c}\text { Entrevista } \\
\text { semiestruturada }\end{array}$ & 10.1.2007 & Sala de RH & Não \\
\hline 9 & $\begin{array}{l}\text { Diretor médico de } \\
\text { operações }\end{array}$ & Estratégica & 1:10h & $\begin{array}{l}\text { Mapa cognitivo } \\
\text { causal }\end{array}$ & 24.1.2007 & $\begin{array}{l}\text { Sala própria } \mathrm{p} / \\
\text { realizar o mapa }\end{array}$ & Não \\
\hline 10 & $\begin{array}{c}\text { Diretora } \\
\text { Assistencial }\end{array}$ & Estratégica & $3: 10 \mathrm{~h}$ & $\begin{array}{l}\text { Mapa cognitivo } \\
\text { causal }\end{array}$ & 22.1.2007 & $\begin{array}{l}\text { Sala própria } \mathrm{p} / \\
\text { realizar o mapa }\end{array}$ & $\begin{array}{l}\text { Realizado em } \\
\text { duas etapas } \\
\text { (necessidade do } \\
\text { respondente) }\end{array}$ \\
\hline 11 & $\begin{array}{l}\text { Consultor técnico da } \\
\text { superintendência }\end{array}$ & Estratégica & $1: 30 h$ & $\begin{array}{l}\text { Mapa cognitivo } \\
\text { causal }\end{array}$ & 24.1.2007 & $\begin{array}{l}\text { Sala própria } \mathrm{p} / \\
\text { realizar o mapa }\end{array}$ & Não \\
\hline 12 & $\begin{array}{l}\text { Gerente do serviço de } \\
\text { epidemiologia }\end{array}$ & Tática & $1: 30 \mathrm{~h}$ & $\begin{array}{l}\text { Mapa cognitivo } \\
\text { causal }\end{array}$ & 18.1.2007 & $\begin{array}{l}\text { Sala própria } \mathrm{p} / \\
\text { realizar o mapa }\end{array}$ & $\begin{array}{l}\text { Primeiro mapa } \\
\text { realizado }\end{array}$ \\
\hline 13 & $\begin{array}{c}\text { Supervisora de } \\
\text { Enfermagem em CTI }\end{array}$ & Tática & 1:30h & $\begin{array}{l}\text { Mapa cognitivo } \\
\text { causal }\end{array}$ & 25.1.2007 & $\begin{array}{l}\text { Sala própria } \mathrm{p} / \\
\text { realizar o mapa }\end{array}$ & Não \\
\hline 14 & $\begin{array}{l}\text { Gerente do serviço de nu- } \\
\text { trição e dietética }\end{array}$ & Tática & $1: 15 h$ & $\begin{array}{l}\text { Mapa cognitivo } \\
\text { causal }\end{array}$ & 25.1.2007 & $\begin{array}{l}\text { Sala própria } \mathrm{p} / \\
\text { realizar o mapa }\end{array}$ & Não \\
\hline 15 & $\begin{array}{l}\text { Médico do time de } \\
\text { Resposta rápida }\end{array}$ & Operacional & $1: 50 \mathrm{~h}$ & $\begin{array}{l}\text { Mapa cognitivo } \\
\text { causal }\end{array}$ & 22.1.2007 & $\begin{array}{l}\text { Sala própria } \mathrm{p} / \\
\text { realizar o mapa }\end{array}$ & Não \\
\hline 16 & $\begin{array}{l}\text { Enfermeira executiva } \\
\text { unidade de internação }\end{array}$ & Operacional & $1: 10 \mathrm{~h}$ & $\begin{array}{l}\text { Mapa cognitivo } \\
\text { causal }\end{array}$ & 22.1.2007 & $\begin{array}{l}\text { Sala própria } \mathrm{p} / \\
\text { realizar o mapa }\end{array}$ & Não \\
\hline 17 & $\begin{array}{l}\text { Médico do centro de } \\
\text { terapia intensiva - CTI }\end{array}$ & Operacional & $1: 30 \mathrm{~h}$ & $\begin{array}{l}\text { Mapa cognitivo } \\
\text { causal }\end{array}$ & 18.1.2007 & $\begin{array}{l}\text { Sala própria } \mathrm{p} / \\
\text { realizar o mapa }\end{array}$ & Não \\
\hline
\end{tabular}


enfermagem das Unidades de Internação onde a estratégia TRR foi implementada e Mestre em Administração pela universidade acima citada.

De forma geral, em função dos procedimentos adotados e já descritos para a coleta de dados, não ocorreram dificuldades relevantes na realização das entrevistas e construção dos mapas cognitivos individuais. A compreensão dos envolvidos sobre os objetivos e procedimentos da coleta de dados mostrou-se bastante satisfatória.

\section{RESULTADOS DA PESQUISA}

A entrevista com o Superintendente, nível Estratégico, relatou que o Sistema de Saúde Mãe de Deus possui Planejamento Estratégico desde 1998, com políticas, diretrizes e metas que são avaliadas sistematicamente. $\mathrm{O}$ Planejamento Estratégico atualmente possui forte ênfase na qualidade médico-assistencial.

O Sistema de Saúde Mãe de Deus utiliza o Balanced Scorecard - BSC no Planejamento Estratégico do hospital com as Perspectivas Financeira, de Cliente e Mercado, de Processos Internos e do Conhecimento e Aprendizado. Contudo, a organização desenvolveu uma quinta perspectiva, chamada de Perspectiva Social, dada a natureza da sua mantenedora e da missão da Instituição. O duplo desafio do hospital é ser um hospital de excelência e prover recursos para projetos sociais da mantenedora.

Em 2000, houve a formulação de um Modelo de Gestão para o Hospital Mãe de Deus, que vem sendo gradativamente implementado a partir do planejamento estratégico. Esse modelo tem uma estrutura básica que agrega simultaneamente a capacidade de gestão, a competência técnica, a responsabilidade social, o desenvolvimento técnico-científico e a pesquisa. Todos esses elementos estão no mesmo plano, onde a estratégia geral é o equilíbrio entre esses quatro pilares que sustentam o modelo de gestão do hospital.

A Implementação do Time de Resposta Rápida (TRR) nas Unidades de Internação está vinculada a uma macroestratégia de diferenciação do hospital no mercado de saúde através da competência técnica. O Time de Resposta Rápida é um grupo médico-assistencial (médicos com formação em Terapia Intensiva) que dá suporte técnicoassistencial em casos de urgências médicas na unidade de internação. Busca-se com a ação desse TRR reduzir as taxas de mortalidade e paradas cardiorrespiratórias nas unidades, elevando os índices de qualidade médicoassistenciais e de segurança para os pacientes. O Time de Resposta Rápida tem demonstrado, através de indicadores, ser um diferencial na gestão de risco e qualidade assistencial do hospital.

Na síntese das entrevistas em profundidade (Fase 1 da pesquisa de campo) com os respondentes dos três Níveis Hierárquicos, quando estes se referiram à implementação do TRR, os mesmos abordaram:

- Nível Estratégico: ter conhecido as estratégias através das reuniões do processo de definição das estratégias. Os respondentes referiram-se à implementação do TRR no HMD como: acompanhada através de indicadores específicos e ferramentas assistenciais, que colaboraram de forma pró-ativa e não reativa para as questões de segurança médico-assistencial.

- Nível Tático: ter conhecido as estratégias através das reuniões e pela participação na elaboração do Planejamento Estratégico. Os respondentes referiram-se à implementação do TRR no HMD como: uma ação integrada, com uma escolha das pessoas com perfil necessário, planejamento centralizado na liderança do projeto, com ações preparatórias para essa estratégia iniciar e com reuniões específicas para a implementação da estratégia.

- Nível Operacional: ter conhecido as estratégias através das reuniões com a diretoria, na apresentação do Planejamento Estratégico e em reuniões com a supervisão da área. Os respondentes referiram-se à implementação do TRR no HMD como: um processo contínuo, constituído passo a passo, implementado através de reuniões do líder com toda a equipe envolvida, havendo acompanhamento dos resultados e alinhamento das ações futuras.

Os dados das entrevistas referentes aos fatores que influenciaram na implementação do TRR foram comparados com os obstáculos descritos por Hrebiniak (2006), referentes às pesquisas de Wharton-Gartner (2003) e da Wharton School of Business and Gartner Inc. (2002), (HREBINIAK, 2006, p. 35). Esses dados e a comparação são apresentados no Quadro 2.

$\mathrm{Na}$ análise dessa comparação, observou-se que os obstáculos descritos por Hrebiniak (2006) não ocorreram na implementação do TRR e que quase a totalidade destes foi revertida em seus opostos, citados pelos respondentes como facilitadores. Esses dados confirmam o sucesso da implementação dessa estratégia. Existiram três obstáculos que parcialmente ocorreram: Conflito de Poder, mas que surgiu num momento posterior sem prejuízo importante para a implementação; Comunicação a todos, pois só os envolvidos foram comunicados no momento da implementação do TRR; e 
Recursos Financeiros, pois a segunda fase dessa implementação ainda não ocorreu.

Por sua vez, os comentários das sínteses dos Mapas Cognitivos Agregados (Fase 2 da pesquisa de campo) por níveis hierárquicos foram:

- Nível Estratégico: na percepção dos respondentes do nível estratégico, os fatores de influência na implementação do Time de Resposta Rápida no HMD foram: Planejamento; Sistema de Informações; Aprendizado Organizacional; Habilidades; Estrutura Organizacional; Cultura; Reconhecimento pelos resultados; Envolvimento e comprometimento das pessoas.

Quadro 2 - Comparação dos fatores de influência na implementação do TRR identificados nas entrevistas com os obstáculos de Hrebiniak (2006)

\begin{tabular}{|c|c|c|c|}
\hline \multicolumn{4}{|c|}{$\begin{array}{l}\text { COMPARAÇÃO DOS OBSTÁCULOS DE HREBINIAK COM OS FATORES DE INFLUÊNCIA } \\
\text { NA IMPLEMENTAÇÃO DO TIME DE RESPOSTA RÁPIDA (ENTREVISTAS) }\end{array}$} \\
\hline $\begin{array}{l}\text { OBSTÁCULOS } \\
\text { (HREBINIAK, 2006) }\end{array}$ & $\begin{array}{l}\text { FATORES DE } \\
\text { INFLUÊNCIA NO TRR }\end{array}$ & COMENTÁRIOS DOS RESPONDENTES & CITADAS POR \\
\hline $\begin{array}{l}\text { 1. Incapacidade de } \\
\text { gerenciar mudanças }\end{array}$ & $\begin{array}{l}\text { Resistência a } \\
\text { mudanças }\end{array}$ & $\begin{array}{l}\text { Ocorreram na parte inicial da implementação por } \\
\text { parte de um pequeno grupo de pessoas (médicos } \\
\text { assistentes). }\end{array}$ & $\begin{array}{l}\text { Nível Tático e } \\
\text { Operacional }\end{array}$ \\
\hline 2. Conflito de poder & Conflito de poder & $\begin{array}{l}\text { Ocorreram após o reconhecimento pelos resultados } \\
\text { ocasionando a saída do líder da implementação. }\end{array}$ & $\begin{array}{l}\text { Nivel Estratégico, } \\
\text { Tático e Operacional }\end{array}$ \\
\hline $\begin{array}{l}\text { 3. Comunicação } \\
\text { inadequada }\end{array}$ & $\begin{array}{l}\text { Comunicação da } \\
\text { estratégia a todos }\end{array}$ & $\begin{array}{l}\text { Foi realizada para todos os envolvidos na imple- } \\
\text { mentação de forma efetiva e insuficiente para as } \\
\text { demais pessoas. }\end{array}$ & $\begin{array}{l}\text { Nível Estratégico, } \\
\text { Tático e Operacional }\end{array}$ \\
\hline $\begin{array}{l}\text { 4. Indefinição de } \\
\text { responsabilidades }\end{array}$ & $\begin{array}{l}\text { Valores e responsabili- } \\
\text { dades compartilhados }\end{array}$ & $\begin{array}{l}\text { Este processo foi muito eficiente e gerou comprome- } \\
\text { timento e valorização entre as pessoas. }\end{array}$ & $\begin{array}{l}\text { Nível Estratégico, } \\
\text { Tático e Operacional }\end{array}$ \\
\hline $\begin{array}{l}\text { 5. Estratégia vaga ou } \\
\text { deficiente }\end{array}$ & Clareza da estratégia & $\begin{array}{l}\text { A estratégia ficou perfeitamente clara para todos os } \\
\text { envolvidos que sabiam seus papéis e os objetivos. }\end{array}$ & $\begin{array}{l}\text { Nível Estratégico, } \\
\text { Tático e Operacional }\end{array}$ \\
\hline $\begin{array}{l}\text { 6. Falta de } \\
\text { comprometimento }\end{array}$ & $\begin{array}{l}\text { Envolvimento e } \\
\text { comprometimento }\end{array}$ & $\begin{array}{l}\text { Na implementação o envolvimento foi total e com- } \\
\text { prometeu toda a equipe potencializando resultados. }\end{array}$ & $\begin{array}{l}\text { Nível Estratégico, } \\
\text { Tático e Operacional }\end{array}$ \\
\hline $\begin{array}{l}\text { 7. Falta de modelo } \\
\text { orientador }\end{array}$ & $\begin{array}{l}\text { Alinhamento à estraté- } \\
\text { gia da Organização }\end{array}$ & $\begin{array}{l}\text { Vinculado a uma estratégia maior e perfeitamente } \\
\text { alinhado a estes propósitos. }\end{array}$ & $\begin{array}{l}\text { Nível Estratégico, } \\
\text { Tático e Operacional }\end{array}$ \\
\hline $\begin{array}{l}\text { 8. Falta de clareza na } \\
\text { estrutura e processo }\end{array}$ & Planejamento & $\begin{array}{l}\text { Realizado de forma participativa e permitindo clare- } \\
\text { za em cada etapa da implementação. }\end{array}$ & $\begin{array}{l}\text { Nível Estratégico, } \\
\text { Tático e Operacional }\end{array}$ \\
\hline $\begin{array}{l}\text { 9. Falta de convicção } \\
\text { na execução }\end{array}$ & Disciplina e habilidade & $\begin{array}{l}\text { As pessoas acreditaram e aderiram ao projeto en- } \\
\text { tendendo e aceitando os benefícios da estratégia. }\end{array}$ & $\begin{array}{l}\text { Nível Estratégico, } \\
\text { Tático e Operacional }\end{array}$ \\
\hline 10. Falta de incentivos & $\begin{array}{l}\text { Valorização dos } \\
\text { resultados }\end{array}$ & $\begin{array}{l}\text { Houve valorização dos resultados obtidos reforçando } \\
\text { o comprometimento das pessoas. }\end{array}$ & $\begin{array}{l}\text { Nível Estratégico, } \\
\text { Tático e Operacional }\end{array}$ \\
\hline $\begin{array}{l}\text { 11. Recursos financei- } \\
\text { ros insuficientes }\end{array}$ & Falta de recursos & $\begin{array}{l}\text { A estratégia ainda não foi completamente implemen- } \\
\text { tada por indefinições de recursos. }\end{array}$ & $\begin{array}{l}\text { Nível Estratégico, } \\
\text { Tático }\end{array}$ \\
\hline $\begin{array}{l}\text { 12. Falta de apoio da } \\
\text { direção }\end{array}$ & Tipo de liderança & Souberam conduzir a estratégia para o sucesso. & $\begin{array}{l}\text { Nível Estratégico, } \\
\text { Tático e Operacional }\end{array}$ \\
\hline
\end{tabular}


Os fatores destacados como de maior influência, cujas relações foram referidas de forma unânime pelos respondentes, foram: envolvimento e comprometimento das pessoas; habilidades; estrutura organizacional; reconhecimento pelos resultados.

Os fatores identificados pelo nível estratégico como dificultadores da implementação dessa estratégia não tiveram destaque nos resultados do Mapa Cognitivo Agregado. Os respondentes desse nível ainda citaram o fator recursos, não elencado inicialmente.

- Nível Tático: na percepção dos respondentes desse nível, os fatores de influência na implementação do Time de Resposta Rápida foram: resistência às mudanças; tipo de liderança; clareza; habilidades; comunicação; medidas de controle; reconhecimento pelos resultados; envolvimento e comprometimento das pessoas e planejamento.

Os fatores destacados como de maior influência, com relações citadas por todos os respondentes do nível hierárquico, foram: envolvimento e comprometimento das pessoas; o planejamento; o tipo de liderança e a clareza.

Os fatores identificados, pelo nível tático como dificultadores da implementação dessa estratégia, não tiveram destaque nos resultados do Mapa Cognitivo Agregado. Ainda foram citados os fatores capacitação e recursos não citados a princípio.

- Nível Operacional: na percepção dos respondentes do nível operacional, os fatores de influência na implementação do Time de Resposta Rápida foram: planejamento; tipo de liderança; clareza; habilidades; comunicação; cultura; reconhecimento pelos resultados; envolvimento e comprometimento das pessoas.

Os fatores destacados como de maior influência foram: envolvimento e comprometimento das pessoas; planejamento; tipo de liderança; cultura.

Os fatores identificados pelo nível operacional como dificultadores da implementação dessa estratégia não tiveram destaque nos resultados do Mapa Cognitivo Agregado. Ainda foram citados os fatores integração, motivação e relacionamento, não elencados inicialmente.

Em linhas gerais, os Mapas Cognitivos Agregados, realizados a partir dos Mapas Cognitivos Individuais dos respondentes da Fase 2 da pesquisa de campo, revelaram diferenças bem características de cada nível hierárquico a respeito dos fatores que influenciaram a implementação do TRR no HMD. Tal pensamento distinto está apresentado no Quadro 3.

Quadro 3 - Fatores de influência na implementação no TRR no HMD identificadas nos mapas cognitivos agregados nos 3 níveis hierárquicos OS FATORES DE INFLUÊNCIA NOS MAPAS AGREGADOS DOS 3 NIIVEIS HIERÁRQUICOS

\begin{tabular}{|c|c|c|c|c|c|c|c|c|c|c|}
\hline \multicolumn{11}{|c|}{ FATORES DE INFLUÊNCIA } \\
\hline $\begin{array}{l}\text { Relação no mapa } \\
\text { Cognitivo agregado }\end{array}$ & 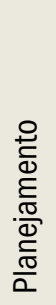 & 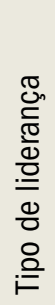 & 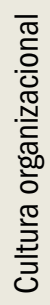 & 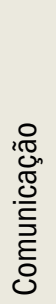 & $\begin{array}{l}\mathscr{D} \\
\frac{0}{0} \\
\frac{\pi}{0} \\
\overline{\overline{0}} \\
\frac{0}{1} \\
\text { I. }\end{array}$ & 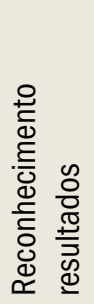 & 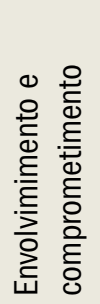 & $\begin{array}{l}\mathbb{N} \\
\frac{\mathbb{U}}{\mathbb{U}} \\
\frac{0}{U}\end{array}$ & 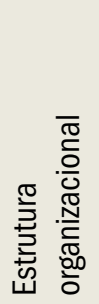 & 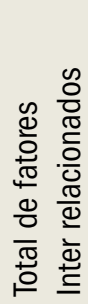 \\
\hline Estratégico & & & & & $x$ & $x$ & $x$ & & $x$ & 4 \\
\hline Tático & $X$ & $x$ & & $x$ & $x$ & $x$ & $x$ & $x$ & & 7 \\
\hline Operacional & $X$ & $X$ & $X$ & $X$ & $x$ & $x$ & $X$ & $x$ & & 8 \\
\hline
\end{tabular}

Nota

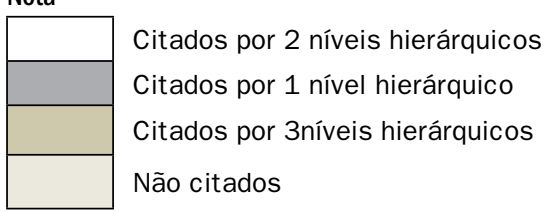




\section{Comparação dos resultados das fases 1 (entrevistas) e 2 (mapas cognitivos) da pesquisa de campo}

Detalhando os comentários sobre os resultados comparativos dos respondentes das Fases 1 e 2 da pesquisa de campo, respectivamente entrevistas em profundidade $e$ mapas cognitivos, identifica-se:

- Tipo de Liderança - os respondentes dos níveis Tático e Operacional valorizaram muito esse fator, para eles determinante para o sucesso da implementação do TRR. Tal escolha confirma a referência de autores como Mintzberg e outros (2006), Freedman (2002) e Mintzberg e Quinn (2001), Robbins (2004) e Kaplan e Norton (2000, p.26), que citam que "se as pessoas no topo não atuarem como líderes vibrantes, as mudanças não ocorrerão e a estratégia não será implementada...". O líder teve um perfil de coaching (preparador) para sua equipe, como referida por Cesar e Coda (2005), que permitiu mais liberdade na equipe operacional.

- Disciplina e Habilidade - houve referência pelos respondentes das Fases 1 e 2, em todos os níveis hierárquicos; foi considerado por estes como mais um fator determinante nesse processo. Robbins (2004) refere que as habilidades pessoais são ativos preciosos. Autores como Freedman (2003), Chaharbagui e Feurer (1995), Moscovici (1999), entre outros, também referem a importância desse fator.

- Envolvimento e Comprometimento das Pessoas - para os respondentes tanto das entrevistas como dos Mapas Cognitivos, em todos os níveis hierárquicos, foi considerado o grande diferencial na implementação do TRR. Tal fator é considerado uma necessidade para a implementação da estratégia por Senge e outros (1999), O'Regan e Ghobadian (2002), Kaplan e Norton (2000). Em todos os níveis hierárquicos e basicamente no nível Operacional, que de fato executa a implementação da estratégia, verificou-se a existência desse sentimento. César e Coda (2005) relacionam o comprometimento ao clima organizacional, aspecto que parece pertinente, pois existiu um clima geral de cooperação nessa implementação.

- Reconhecimento pelos Resultados - foi citado por todos os níveis de forma quase unânime. Foi identificado como um fator que alimentou o ciclo motivacional do grupo operador. Robbins (2004) e César e Coda (2005) referem que as pessoas altamente motivadas com o trabalho estão emocionalmente mais comprometidas com ele. A importância da recompensa para que as pessoas disponibilizem suas habilidades e se comprometam é citada por Mayo (2003), Mintzberg e Quinn (2001). Hrebiniak
(2006) relaciona esse fator ao apoio da Direção, que pareceu ocorrer de forma ampla nessa implementação.

- Complexidade dos Processos - todos os níveis hieráquicos definiram que o processo de implementação do TRR não foi complexo e que a simplicidade desse processo foi um facilitador. Freedman (2003) refere a necessidade de redução de complexidade como um elemento essencial para a implementação.

- Alinhamento Estratégico da Organização - foi citado em todos os níveis hierárquicos, mas com mais ênfase nos níveis Estratégico e Tático, que possuem maior conhecimento desse processo, razão pela qual se acredita que o nível operacional não o destacou tanto. O nível Tático entendeu ser este o fator de convergência, o que é reforçado no referencial de Freedman (2003), que o aborda como um elemento essencial à implementação da estratégia.

- Problemas Externos à Empresa - tanto nos respondentes das entrevistas como dos Mapas Cognitivos, somente os níveis Estratégico e Tático citaram esse fator. O nível operacional não referiu tal fator; esse fato reforça o que a literatura refere: a operação não se envolve com questões mais globais, relacionadas às estratégias.

Existiu diferenciação entre os resultados dos níveis hierárquicos dos Mapas Cognitivos em relação aos das entrevistas. Considerando-se a comparação da utilização dos Mapas Cognitivos com as entrevistas, observou-se que: 1) quanto ao método utilizado para a coleta dos dados, a construção de Mapas Cognitivos Individuais foi mais trabalhosa e exigiu um planejamento prévio bem detalhado para estabelecer a logística necessária, com maior tempo consumido; 2) quanto aos respondentes, os que participaram da construção dos Mapas Cognitivos Individuais foram mais exigidos na elaboração de um raciocínio lógico e se focaram mais no tema proposto do que os respondentes das entrevistas; 3 ) quanto à quantidade dos fatores, o número total de fatores influenciadores foi semelhante, o que era esperado, pois foi apresentada uma relação de fatores descritos na literatura que serviu de orientação para os respondentes de ambos os métodos. Contudo, se analisado o quantitativo desses mesmos fatores em cada nível hierárquico, nos Mapas Cognitivos Individuais houve uma redução de fatores mencionados em relação às entrevistas; 4) quanto ao conteúdo, observou-se mais riqueza nos Mapas Cognitivos Individuais, pois os respondentes aprofundaram suas análises pela necessidade (contida nesse método) de relacionar os fatores entre si, numa relação de causa e efeito. Isto explica a menor convergência entre os dados coletados nos mapas, em cada 
nível hierárquico, em relação às entrevistas, diferenciando mais os níveis hierárquicos entre si (nos mapas).

Nos Mapas, houve a possibilidade de observar o pensamento reinante em cada nível hierárquico, fruto da abrangência de conhecimento e experiências dos respondentes. Esse detalhamento individual possibilitou presumir o entendimento de cada respondente sobre o tema proposto. Nas entrevistas, todos os fatores foram citados pelos respondentes de forma despreocupada em relação aos vínculos causais, o que gerou alta convergência entre as respostas. Não havia necessidade de estabelecer a relação entre eles. Por essa razão, os fatores dificultadores foram mais citados nas entrevistas do que nos Mapas Cognitivos Individuais, onde os fatores dessa natureza não foram relevantes, visto que a estratégia escolhida teve sucesso na sua implementação, ao menos até o momento de elaboração deste artigo.

\section{CONSIDERAÇõES FINAIS}

Cada vez mais os estudos demonstram que os aspectos subjetivos não podem ser desconsiderados na implementação de estratégias. É pertinente entender parte dessa subjetividade através de ferramentas que representem essa interpretação mental que as pessoas fazem sobre eventos que ocorrem nas organizações, assim como os Mapas Cognitivos.

Em todos os níveis hierárquicos da empresa, tanto nos respondentes das entrevistas quanto nos dos mapas cognitivos, houve concordância de que o fator "Envolvimento e Comprometimento das Pessoas" foi o mais relevante na implementação da estratégia em estudo. O fato de as pessoas se envolverem e estarem de fato comprometidas, acreditando na estratégia (desde a liderança até a operação) e conhecendo seu papel em sua implementação, foi o que mais determinou o sucesso desse processo, segundo os respondentes. Considerando que o fator humano foi o maior diferencial na implementação da estratégia no ambiente hospitalar, em função da relevância das capacidades e conhecimento profissionais para a organização, é possível inferir que esse resultado deva repetir-se em outras empresas com características similares e que tenham seu diferencial nas pessoas, as quais, agindo de forma complementar, multidisciplinar ou intersetorial, contribuem para a materialização das estratégias.

Analisando somente os respondentes dos mapas cognitivos, observou-se haver maior afinidade de pensamento entre os respondentes dos níveis Tático e Operacional, quanto aos fatores que influenciaram na implementação do TRR no HMD. Entretanto, quase todos os fatores destacados pelo Nível Estratégico estão incluídos nas relações identificadas nos outros níveis hierárquicos. Tal fato demonstra certa coerência entre os níveis hierárquicos da empresa e é configurado pelo fato de quase que os fatores destacados pelo Nível Estratégico, em sua totalidade, estão também identificados nos outros dois níveis.

No entanto, os mapas cognitivos revelaram características distintas no grupo de respondentes de cada nível hierárquico, mais evidentes que as entrevistas, a respeito dos fatores que influenciaram na implementação da estratégia estudada:

a) O Nível Estratégico confirma seu foco em uma visão macro da organização hospitalar, salientando fatores como Estrutura Organizacional, Aprendizado Organizacional e Sistema de Informações, fatores bem abrangentes e de suma importância no processo da estratégia não referidos pelos outros níveis hierárquicos. Disciplina e habilidades obtiveram maior ênfase no nível Estratégico, em relação ao nível Tático, e este também destacou mais esse fator em relação ao Operacional. A partir de tal evidência, conclui-se que quanto maior o nível hierárquico, maior é a preocupação com o fator Disciplina e Habilidade da equipe responsável pela implementação da estratégia, na organização estudada. b) No Nível Tático, verificou-se maior convergência entre os mapas individuais, mostrando uma concordância entre os respondentes desse nível. Destacaram-se os fatores Clareza da Estratégia e Alinhamento Estratégico, demonstrando a preocupação existente, nesse nível, com o desdobramento do processo da estratégia para o nível operacional. Destacou-se ainda o fator Medidas de Controle do Processo, uma preocupação com gestão de processos, bem própria desse nível. O Planejamento também foi um fator de destaque.

c) No Nível Operacional, houve destaque na Cultura Organizacional, evidenciando o sentimento de "pertença" necessário para o comprometimento das pessoas com a estratégia. Comunicação também foi destaque, visto que o nível operacional é a ponta dessa cadeia hierárquica e esse fator é determinante para o entendimento e a participação desse nível no processo da implementação da estratégia.

d) O Tipo de Liderança e Planejamento foram destacados pelos níveis Tático e Operacional, apresentando a relevância desses fatores no processo de implementação, em virtude de executarem de fato a estratégia e, pela mesma razão, também salientaram a Resistência à Mudança, como fator de influência, não destacado pelo nível Estratégico. 
Cada nível hierárquico, de forma mais evidente nos mapas estratégicos que nas entrevistas, demonstrou sua característica de acordo com a posição que ocupa na organização, responsabilidade e conhecimento agregados à função. Pôde-se evidenciar a macro visão do nível estratégico, focada nas questões mais abrangentes de estrutura e aprendizado organizacional; a preocupação do nível Tático com o alinhamento da estratégia, planejamento e a liderança necessárias às questões funcionais e à logística da implementação e, por fim, o nível Operacional focado nas questões próprias da execução in loco, influenciadas pelo tipo de liderança, reconhecimento pelos resultados e a cultura organizacional. Os fatores evidenciados nos níveis Tático e Operacional demonstram que são estes que executam, de fato, a estratégia em estudo.

Constatou-se, a partir dessa pesquisa, um alinhamento entre os três níveis hierárquicos da empresa quanto à implementação dessa estratégia, a qual acredita-se teve êxito pela congregação de múltiplos fatores que poderiam facilmente ter sido obstáculos, mas que, pelo tipo de planejamento, acompanhamento e envolvimento das pessoas e das lideranças, tornaram-se facilitadores para garantir esse sucesso. A pesquisa analisou uma estratégia de sucesso e dessa forma não houve a exploração de fatores dificultadores, pois eles não tiveram relevância no estudo.

Diante dos resultados dessa pesquisa e das conclusões decorrentes, recomenda-se, do ponto de vista acadêmico, que: o estudo seja reproduzido em outras instituições hospitalares ou não; a escolha, para fins de análise, de uma implementação de estratégia que não tenha obtido o sucesso esperado, para possibilitar a exploração principalmente dos fatores dificultadores envolvidos nessa etapa do processo estratégico, explore "o que não deu certo" nesse processo. No que tange ao gerenciamento de empresas, recomenda-se a utilização do Mapeamento Cognitivo como uma ferramenta de pesquisa organizacional, para analisar os fatores de influência na implementação das estratégias em ambiente empresarial, visando replicar os diferenciais atingidos por essa técnica de estudo.

\section{REFERÊNCIAS}

BASTOS, A. V. T. Mapas cognitivos e a pesquisa organizacional: explorando aspectos metodológicos. Estudos de Psicologia, 2002, v. 7, (número especial), p. 65-77. Disponível em http://www.scielo.br/pdf/episic/v7nspe/ a08v7esp.dft . Acesso em 03.01.2006.

BASTOS, A. V. T. Mapas cognitivos: ferramentas de pesquisa e intervenção em processos organizacionais. In: ENCONTRO NACIONAL DE ESTUDOS
ORGANIZACIONAIS DA ASSOCIAÇÃO NACIONAL DOS PROGRAMAS DE PÓS-GRADUAÇÃO EM ADMINISTRAÇÃO, 1, 2000, Curitiba. Anais Curitiba: ANPAD, 2000.

CESAR, A. M. R. V; CODA, R. Falar da dor, esvasiar o peito, ancorar o coração: uma metodologia para gestão de pessoas em situações de mudanças organizacionais. In: ENCONTRO NACIONAL DA ASSOCIAÇÃO DOS PROGRAMAS DE PÓS-GRADUAÇÃO EM ADMINISTRAÇ̃̃O, 29, 2005, Brasília. Anais. Brasília: ANPAD, 2005.

CHAHARBAGHI, K; FEURER, R. Strategy development: past, present and future. Management Decision, v. 33, n. 6, 1995, p. 11-21. MCB University Press, 0025-1747.

COHN, A; ELIAS, P. E. M. Saúde no Brasil: políticas e organização de serviços. 6. ed. São Paulo: Cortez; São Paulo: CEDEC, 2005

FREEDMAN, M. The genius is in the implementation. Journal of Business Srategy. Mar./Apr., p. 26-31, 2003.

HREBINIAK, L. Fazendo a estratégia funcionar: o caminho para uma execução bem-sucedida. Porto Alegre: Bookman, 2006.

JARDIM, S. B. Mapas cognitivos: um caminho para construir estratégias. Análise, v. 12, n. 2, p. 89-119, 2001

KAPLAN, R. S; NORTON, D. P. Organização orientada para a estratégia: como as empresas que adotaram o balanced scorecard prosperaram no novo ambiente de negócios. 6. ed. Rio de Janeiro: Campus, 2000.

MAYO, Andrew. O valor humano da empresa: valorização das pessoas como ativos. SãoPaulo: Pearson - Prentice Hall, 2003.

MEZOMO, J. C. Gestão da qualidade na saúde: princípios básicos. São Paulo: J. C. Mezomo, 1995.

MINTZBERG, H; QUINN, J. B. O processo da estratégia. 3. ed. Porto Alegre: Bookman, 2001.

MINTZBERG, H; QUINN, J. B; LAMPEL, J; GHOSHAL. O processo da estratégia: conceitos, contextos e casos selecionados. 4. ed. Porto Alegre: Bookman, 2006.

MOSCOVICI, F. Equipes dão certo: a multiplicação do talento humano. 5. ed. Rio de Janeiro: José Olympio, 1999.

O'REGAN, N; GHOBADIAN, A. Effective strategic planning in small and medium sized firms. Management Decision, v. 40, n. 7, p. 663-671, 2002 Disponivel em http:www.emeralddinsight.com/0025-1747.htm. Acesso em 05.05.2006.

OLIVA, F. A; BORBA, V. R. BCS - Balanced Scorecard: ferramenta gerencial para organizções hospitalares. São Paulo: Iátria 2004.

PIDD, M. Modelagem empresarial: ferramentas para a tomada de decisão. Porto Alegre: Bookman, 2001. 
PORTER, M. E; TEISBERG, E. O. Repensando a saúde: estratégias para melhorar a qualidade e reduzir os custos. Tradução de Cristina Bazan. Porto Alegre: Bookman, 2007.

RIBEIRO, T. S. S. O conceito de responsabilidade social sob a ótica dos dirigentes da Agência de Fomento do Estado da Bahia - DESENBAHIA. Dissertação de Mestrado em Administração de Empresas, Escola de Administração, Universidade Federal da Bahia, Bahia, 2003. Disponível em http://www. adm.ufba.br/disserta\%E7\%E3o2.pdf. Acesso em 03.01.2006.

ROBBINS, S. P. Fundamentos do comportamento organizacional. 7. ed. São Paulo: Prendice Hall, 2004.

RUAS, E. B. Criação de indicadores estratégicos para o Instituto de Pesquisas Tecnológicas do Estado de São Paulo S.A - IPT. RAE-eletrônica, v. 2, n. 1, jan.-jun, 2003. Disponível em http://www.rae.com.br/eletronica/ index.cfm?FuseAction=Artigo $\& I D=1872 \& S e c a 0=2 \% C 2 \% B A P W C \& V o l u m$ $\mathrm{e}=2 \&$ Numero= $1 \& A n o=2003$. Acesso em 19.05.2006.
SENGE, P. M; KLEINER, A; ROBERTS, C; ROSS, R; ROTH, G; SMITH, B. A dança das mudanças: os desafios de manter o crescimento e o sucesso em organizações que aprendem. 3. ed. Rio de Janeiro: Campus, 1999.

SILVA. E. D. Barrera a la implementación estratégica: el caso Copel. In: ENCONTRO NACIONAL DA ASSOCIAÇÃO DOS PROGRAMAS DE PÓS-GRADUAÇÃO EM ADMINISTRAÇÃO, 25, 2001, Campinas. Anais. Campinas: ANPAD, 2001.

THOMPSON Jr. A; STRICKLAND III, A. J. Planejamento estratégico: elaboração, implementação e execução. São Paulo: Pioneira, 2000.

VASCONCELOS FILHO, P; PAGNONCELLI, D. Construindo estratégias para vencer: um método prático, objetivo e testado para o sucesso da sua empresa. 10. ed. Rio de Janeiro: Campus, 2001.

ZANON, U. Qualidade da assistência médico hospitalar: conceito, avaliação e discussão dos indicadores de qualidade. Rio de Janeiro: MEDSI, 2001 